computer engineers must also grapple with the problem of standardizing computer software in a way that manufacturers and businesses find appealing. One leading option is "high-performance Fortran", which adapts one of the oldest and most widely used computer languages to massively parallel supercomputers.

Another avenue is to combine the best features of parallel and traditional vector supercomputing, which use a much more efficient linear method of calculation. By September, Fujitsu plans to start selling a supercomputer capable of performing at 355 billion operating instructions per second, or gigaflops, that will use a combination of the two technologies and do in a minute what would take 10 days on a typical desktop workstation. Fujitsu claims the machine will be able to use existing software, while also having the performance advantages of parallel processing. Cray also plans to roll out a hybrid system that would allow users to attach parallel processing features to their current supercomputers. And in June, Oak Ridge National Laboratory in Tennessee will begin using an Intel Paragon supercomputer that will operate at a peak of 150 gigaflops.

Further down the line, the Japanese project combines research on massively parallel machines with optical computing, using beams of light rather that electronic impulses to transmit data. The Japanese have urged researchers from around the world to join the project. Although cost-sharing might sound appealing at a time when EC scientists struggle with the uncertainties of a divided Europe and US scientists are weaning themselves from a shrinking defence department research budget, so far few companies have taken Japan up on the offer - another indication of the intense competition in the field.

Michael Mills

\section{Hubble repairs to top active year in space}

The US National Aeronautics and Space Administration (NASA) hopes that 1993 will bring an end to its biggest public relations headache of recent years as space programmes around the world prepare for 12 months of down-to-earth politicking as well as extraterrestial exploration.

In December a seven-member crew, including European astronaut Claude Nicollier, will attempt to rehabilitate the Hubble Space Telescope. In a series of complex space walks, the astronauts will install a set of corrective devices to compensate for flawed optics in the $\$ 1.5$ billion orbiting telescope, launched in 1990. Even with the defect, scientists have been able to carry out a range of research projects, including searching for evidence of black holes in distant galaxies. However, the repair mission is a prerequisite for other such eagerly awaited efforts as measuring the rate of expansion of the Universe.

In April the same shuttle, the Endeavour, will try to retrieve the European Space Agency's Eureca satellite. Placed in orbit this past July, Eureca carries experiments to determine the effects of radiation and weightlessness on such objects suspended outside the satellite as photoelectric cells and plant spores. It is designed to be launched repeatedly after being plucked from orbit and returned to Earth.

In August, NASA's Mars Observer spacecraft is expected to begin orbiting the red planet. Meanwhile, the space agency's Magellan probe of Venus is expected to cease operations in May.

As usual, most new scientific and science-related spacecraft in 1993 will be launched on unmanned expendable rockets.
Geologists, oceanographers and others who events on the Earth's surface will benefit from two new satellites. In September,

France will launch its SPOT-3 remote-sensing spacecraft, replacing the ageing SPOT2 satellite, and next month the US government had planned to launch its Landsat 6 remote-sensing spacecraft to replace its Landsat 4 and Landsat 5 spacecraft, which have exceeded their scheduled lifetimes. But a defect in the spacecraft's solar panels is expected to cause an indefinite delay.

Other significant scientific payloads include the launch in August of NASA's Sea use remote-sensing spacecraft to monitor

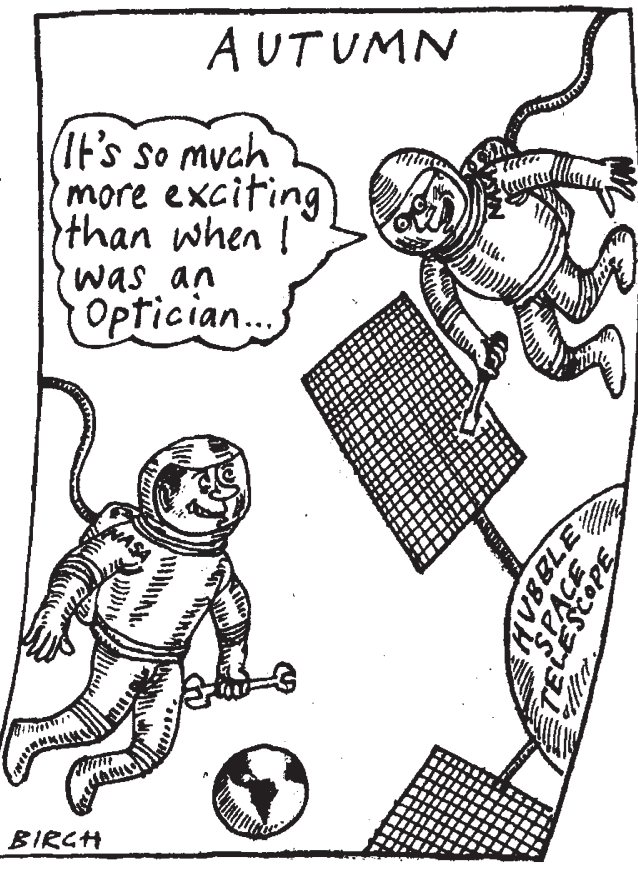

Wide-Field Sensor spacecraft to monitor chlorophyll levels and improve understanding of the global carbon cycle; the launch this month of Brazil's first homemade satellite, to relay environmental data, and next month's launch of Astro-D, Japan's X-ray satellite. The US Defense Department also plans to orbit a scientific spacecraft, known as Alexis, carrying both X-ray telescopes and an experiment to monitor interference with radio transmissions.

Several spacecraft will explore solar physics. NASA's Wind spacecraft, due to be launched next December, will work in concert with Japan's Geotail spacecraft launched in 1991. The Russian space agency's principal scientific launch this year will be a pair of spacecraft to monitor interactions between the solar wind and the Earth's magnetosphere.

Russia also has plans for three manned flights to dock with the Mir space station, including a flight in July featuring a threeweek visit by a French cosmonaut. In November, a Russian cosmonaut is scheduled to fly on a US space shuttle mission, setting the stage for a visit in 1994 by a US astronaut aboard Mir.

However, despite all the activity on launch pads and control rooms around the globe, the most far-reaching developments affecting space may occur in legislative chambers and government offices. In the Commonwealth of Independent States, officials are trying to continue a vibrant space effort in the midst of continuing economic and political turmoil. Compounding the problem is squabbling among the three republics with the greatest interest in space: Russia, which builds most spacecraft and rockets; Kazakhstan, which is the launch and landing site for most missions; and Ukraine, which is home to some manufacturing and telemetry facilities. Simultaneously, the member countries of the European Space Agency are attempting to forge closer relations with the massive post-Soviet space apparatus in an era of tight budgets on both sides.

In the United States, the Clinton-Gore administration and a substantially new Congress are expected to rekindle longstanding political battles relating to space. For example, as a US senator, Vice President-elect $\mathrm{Al}$ Gore badgered reluctant Pentagon officials into approving access for environmental researchers to previously secret measurements made by US spy satellites. As chairman of the National Space Council, Gore may be able to make the military respond more quickly.

And in the US Congress, the planned space station Freedom is likely to be the most contentious issue in space policy. During the presidential campaign, Clinton and Gore voiced support for Freedom. But it is far from clear that Congress, faced with stiff competition for a tight budget, will hold to past agreements to build the $\$ 37$-billion orbiting platform.

Vincent Kiernan 